\title{
O meu itinerário com o pensamento de Paul Tillich ${ }^{1}$
}

\author{
Etienne Alfred Higuet ${ }^{2}$
}

\section{RESUMO}

Escrito em vista de uma Aula Magna, quando se encerrava um ciclo de vida acadêmica, o texto é um ensaio de autobiografia intelectual, dedicado à convivência do autor com o pensamento de Paul Tillich durante mais de cinquenta anos. Privilegiou-se o pensamento político, em relação com a perspectiva histórica e escatológica, e a análise religiosa da cultura, colocando em segundo plano a reflexão epistemológica e a concepção de Deus. Todos os exemplos foram tirados de textos interpretativos do autor, instaurando quase sempre um diálogo com diversos aspectos da cultura contemporânea, principalmente brasileira. Nas considerações finais foram lembrados os cuidados a serem tomados na atualização de um autor de referência, num tempo e num ambiente diferentes dos seus.

Palavras-chave: Paul Tillich, história de vida, teologia política, religião, cultura.

\section{MY ITINERARY WITH THE THOUGHT OF PAUL TILLICH}

\begin{abstract}
This paper was written for a master lecture by reason of a former academic work life end. It is an essay of intellectual autobiography, which is dedicated to the author's experience with the thought of Paul Tillich for over 50 years. On the main frame there are the political thought in relation to the historical and eschatological perspective, and on the reli-
\end{abstract}

1 Este texto é a versão retrabalhada da aula inaugural do Programa de Pós-Graduação em Ciências da Religião da Universidade Metodista de São Paulo em março de 2014.

2 Doutor em Ciências teológicas e religiosas pela Universidade Católica de Louvain (Bélgica). Professor aposentado do Programa de Pós-Graduação em Ciências da Religião da Universidade Metodista de São Paulo. Professor visitante na Universidade do Estado do Pará. Presidente da Associação Paul Tillich do Brasil. E.mail: ethiguet@uol.com.br. Lattes: http://lattes.cnpq.br/5600938581821983. 
gious analysis of culture, having in the background the epistemological reflection and the conception of God. All examples were taken from the interpretative texts of the author, by frequently assuming a dialogue with various aspects of contemporary culture, particularly Brazilian's culture. Final considerations remember the care needed for a reference author in an environment and time different from his very environment and time. Keywords: Paul Tillich, life story, political theology, religion, culture.

\section{Introdução}

O título dado à presente aula já indica que o pensamento de Paul Tillich estará no centro da reflexão, mas que será situado dentro de um itinerário pessoal de vida de quase cinquenta anos. Ouvi falar em Tillich pela primeira vez em 1965, pouco depois da morte dele, através de um artigo na revista Informations catholiques internationales, dedicado à sua vida e ao seu pensamento. Estava cursando o primeiro ano de Teologia e vivíamos na euforia da conclusão do Concílio Vaticano II, destacando a sua dimensão ecumênica. Havia uma foto de Tillich junto com o cardeal belga Léon-Joseph Suenens, que tinha sido um dos líderes do Concílio. Como já era intelectualmente um pouco rebelde, comecei a me interessar pela teologia protestante, que não era sequer mencionada nas aulas de Teologia Dogmática, a não ser para criticá-la. Contudo, seguindo os passos do Concílio, alguns professores já manifestavam certa abertura - embora bastante crítica -, em particular na área bíblica, com os trabalhos de Oscar Cullmann e Rudolf Bultmann, por exemplo. Um livro que me marcou bastante na época foi Honest to God, do bispo anglicano John Robinson, que apresentava Tillich, junto com Bonhoeffer, como teólogo da secularização e inspirador da "Teologia da Morte de Deus". Na ocasião do Concílio, as editoras francesas, inclusive católicas, começaram a publicar mais traduções dos grandes teólogos protestantes do século XX, entre outros, Paul Tillich.

Pensando em estudos teológicos futuros, comecei a estudar alemão, junto com alguns colegas e, nas férias de agosto de 1966, fiz o meu primeiro estágio linguístico na cidade alemã de 
Marburg, sede de uma universidade fundada na época de Lutero. Fiquei hospedado numa espécie de "república", onde havia alguns estudantes de teologia protestante. Eles me indicaram alguns livros em edição de bolso (Bultmann, Barth e Tillich), que comprei na livraria universitária Elwert. De Tillich, adquiri três coletâneas de textos: Auf der Grenze (Na fronteira, porque incluía o ensaio autobiográfico de 1936) (TILLICH, 1962), Der Protestantismus als Kritik und Gestaltung (sobre o princípio e a estruturação protestantes) (TILLICH, 1966), e Für und wider den Sozialismus (Pro e contra o socialismo) (TILLICH, 1969). De volta na Bélgica, iniciei a leitura de alguns textos, sobretudo em vista de aprimorar o meu conhecimento do alemão instrumental, sem pensar ainda numa pesquisa específica. Em setembro de 1968, voltei para Lovaina, onde tinha cursado parte das graduações em filologia clássica e filosofia, para ingressar na Schola Maior (curso superior) de teologia. Passei o primeiro ano, que era também o meu último ano de seminário, no Collegium pro America Latina em vista de me preparar para uma missão na América Latina.

O primeiro ano da Schola Maior - chamado Bacharelado era introdutório, com muitas aulas, contemplando praticamente todas as disciplinas do currículo teológico. Tendo um bom conhecimento do grego, eu me destinava aos estudos de Novo Testamento, mas, quando se tratou de escolher uma especialização, no início do segundo ano, mudei de ideia e escolhi a Teologia Dogmática. Queria, sobretudo, estudar os problemas mais atuais, numa atmosfera que incluía a persistência do clima de maio de 1968, o movimento estudantil, as perspectivas revolucionárias na América Latina e a presença do marxismo. ${ }^{3}$ Parecia-me que o estudo da teologia dogmática ou sistemática seria mais condizente com as questões religiosas e teológicas, mas também sociais e políticas da época. Logo em seguida chegaram a Teologia da

Tive a oportunidade de participar de um grupo de estudos sobre Marx, coordenado por Otto Maduro, que estava preparando o doutorado em ciências sociais. Mais tarde ele se tornaria famoso por trabalhos em sociologia da religião, em consonância com a Teologia da Libertação. 
Esperança de Moltmann, a Teologia Política de Metz e a Teologia da Libertação.

Fiquei logo atraído por um grande professor: Adolphe Gesché, que renovava completamente a linguagem teológica. ${ }^{4}$ Ele aceitou a orientação do meu Mémoire de Licence (que corresponderia atualmente a uma dissertação de mestrado). Tinha retomado a leitura de Tillich, agora sistematicamente e, em acordo com o meu orientador, resolvi escolher o tema da utopia, muito presente nos escritos de Tillich sobre o socialismo religioso. Pude aproveitar a recente publicação das obras completas em alemão (Gesammelte Werke), 14 volumes publicados pela Evangelisches Verlagswerk, e também os recursos do Arquivo Tillich (Göttingen, depois Marburg), graças à diligência e aos conselhos preciosos da saudosa Frau Gertraut Stöber, responsável pelo Arquivo. Ela me mandou literatura primária inédita e literatura secundária, especialmente teses, que reproduzi em fotocópias, microfichas e microfilmes. Participei também de alguns colóquios da Deutsche Paul Tillich Gesellschaft na Academia evangélica de Hofgeismar, em Hessen. A dissertação saiu como "O conceito de Utopia na teologia de Paul Tillich”. Ela não chegou a ser publicada, mas retomei o essencial do seu conteúdo em vários artigos publicados no Brasil ao longo do tempo. ${ }^{5}$

\section{Teologia e política}

O problema da utopia se colocou para Tillich no contexto da sua participação no movimento dos socialistas religiosos, entre 1919 e 1933. Surgiu a partir da contradição existente entre as utopias imanentes, especialmente socialistas e as concepções

4 Ele era autor de inúmeros artigos, que ele publicou tardiamente em forma de livros, sob o título geral: "Deus para pensar". Os livros foram traduzidos em português e publicados pelas Edições Paulinas, em edição organizada pelo saudoso Afonso Maria Ligório Soares. Os textos constituem até hoje uma leitura muito valiosa. Vale assinalar que Adolphe Gesché foi também orientador de doutorado de Clodovis Boff, Ivone Gebara e Antonio Manzatto.

5 Esses artigos foram publicados recentemente no livro: "A teologia de Paul Tillich. Utopia, esperança e socialismo”, em 2017, pela Fonte Editorial de São Paulo. 
transcendentalistas, centradas na esperança no além, do protestantismo luterano. Num clima de decadência da civilização burguesa, ao sair da primeira guerra mundial, o tempo parecia maduro para a reorganização dos valores culturais, no sentido de uma sociedade mais justa e igualitária. Os socialistas religiosos queriam mostrar que havia um necessário compromisso do cristianismo com este ideal.

A argumentação de Tillich era essencialmente antropológica: "Ser humano significa criar utopias" (Mensch sein heisst Utopien haben) (TILLICH, 1969, p. 136). A aptidão à utopia resulta, em primeiro lugar, da constituição do ser humano como liberdade finita e ser histórico. Ele é o "ser-que-possui-a-possibilidade", isto é, a capacidade, ligada ao conhecimento da situação, de superar o dado de modo ilimitado. Contudo, a existência atual do ser humano está alienada do seu ser essencial, o que faz que toda realização nas condições da existência seja marcada pela ambiguidade. Há sempre uma mistura de ser e não ser, de sentido e não sentido. É por isso que nasce no coração do ser humano uma insatisfação fundamental, uma espera do totalmente outro e totalmente novo, cuja expressão é a utopia. A utopia é um signo que nos remete à verdadeira essência do ser humano, que ela coloca frente à existência, como julgamento do presente e norma do futuro. A utopia mais poderosa na sociedade moderna é sem dúvida a ideia que o progresso científico e técnico produzirá uma sociedade que atenda a todas as necessidades humanas, superando a fome e a pobreza, a doença e até a morte, num mundo sem conflitos e sem sofrimentos.

O objetivo central do movimento socialista é produzir essa sociedade ideal, depois de superar as contradições do mundo presente. Mas por causa da finitude e da alienação, o socialismo é também profundamente ambíguo. Se, por um lado, a utopia é uma necessidade, pois "Homens e culturas sem utopia permanecem dependentes do presente e recaem rapidamente no passado" (TILLICH, 1969, p. 175), por outro lado, a utopia não está desprovida de perigos. Isso se aplica particularmente ao socialismo: pela sua atitude de espera, o socialismo possui um caráter profético, mas 
está constantemente ameaçado de cair na objetivação da espera, no utopismo ou na resignação. O utopismo é a absolutização de uma possibilidade finita. A dificuldade é de se opor ao utopismo sem perder a energia da exigência e da paixão da espera. Foi a ideia do Kairós, do tempo favorável, que permitiu valorizar a importância do momento histórico em vista da produção do futuro, sem se deixar prender pelo utopismo. O Kairós indica que a luta por uma nova ordem social não pode levar à realização expressa na ideia de Reino de Deus, mas que um tempo determinado exige tarefas determinadas, que podem levar a realização fragmentária do ideal do Reino. "O Reino de Deus ficará sempre transcendente, mas aparecerá como julgamento pronunciado sobre uma forma dada de sociedade e como norma de uma sociedade por vir" (TILLICH, 1965, p. 46).

Uma primeira forma de utopismo consiste em querer tirar o ser humano da alienação, atacando apenas um aspecto da sua insatisfação fundamental: técnica, racional, individual, social ou espiritual. Ora, a alienação atinge o ser humano em todas as dimensões do seu ser. Um segundo risco consiste em acreditar na possibilidade da realização do Incondicionado ${ }^{6}$ num ponto do espaço e do tempo, com a ajuda da liberdade e da ação. O utopismo espera tudo da liberdade, esquecendo o substrato natural, irracional, inconsciente, demônico da existência humana. A fé no progresso gradual e indefinido da modernidade burguesa é talvez a forma mais perversa do utopismo. Mas pensar que as tensões e contradições deixarão de existir numa possível sociedade sem classes, anarquista e igualitária, é também uma forma de utopismo irrealista. A decepção metafísica, com suas consequências, o fanatismo e o terror, o cinismo e a indiferença, pertencem essen-

6 Para Tillich, o Incondicionado não é uma realidade nem uma essência, não é um ente particular que poderíamos chamar de Deus, mas é uma qualidade da experiência, que faz dela uma experiência propriamente religiosa. Caracteriza o qjue no toca de modo último, incondicionado. Seria um grande erro entender sob o conceito de incondicionado um ser cuja existência possa ser discutida. É uma qualidade que experimentamos no encontro com a realidade, experiência que inclui a exigência incondicionada de reconhecer a manifestação divina através dos símbolos produzidos pela cultura. 
cialmente a toda utopia, assim como a toda divinização idolátrica de uma realidade ou de um momento histórico particular.

O utopismo é superado pelo espirito da utopia, identificado com o espírito profético. Fruto da inquietude essencial do espírito divino e humano, ele é a força de transformação histórica que nasce da utopia e a transcende. É o elemento da utopia que dá força revolucionária e transformadora aos objetivos sociais e políticos. A representação ideal do futuro é necessária, ao mesmo tempo, em vista de uma crítica operante da realidade e da transformação da mesma. O espírito da utopia é o elemento de fé, de ruptura da finitude, que está presente na utopia. O espírito da utopia preserva dois elementos indissociáveis presentes nos movimentos utópicos: o que constitui literalmente a utopia como tal, isto é, a superação de todas as condições da realidade espaço-temporal, a espera de um Reino além do espaço e do tempo; e o que faz da utopia uma força de renovação histórica: a superação das condições da realidade espaço-temporal presente, a espera de outro reino, mesmo se ainda não for o Totalmente-Outro e for um reino provisório e fragmentário.

Em setembro de 1971, iniciei o doutorado, com um projeto mais ambicioso: desenvolver o correspondente da utopia na teologia cristã: a escatologia, a partir da leitura da integralidade da Teologia Sistemática. O meu orientador - era o mesmo - me incentivava muito, pois seria a primeira tese sobre Tillich na Faculdade de Teologia de língua francesa. Depois do primeiro ano (1971-72), consegui uma bolsa DAAD para pesquisar na Alemanha. Voltei então a Marburg, trabalhando sob a supervisão do professor Karl-Heinz Ratschow, que era na época a principal figura da Deutsche-Paul-Tillich-Gesellschaft. Passei lá dois semestres muito proveitosos e muito felizes. Trabalhei na tese mais dois anos na Bélgica, paralelamente ao trabalho pastoral na região industrial de Charleroi. Consegui entregar o trabalho pronto em junho de 1975 e a defesa foi marcada par o dia 15 de setembro. No dia 10 de outubro, embarcava em Rotterdam rumo ao Brasil, desembarcando em Santos no dia 03 de novembro. Com 
o "jeitinho brasileiro", o bispo de Lins, Dom Pedro Paulo Koop, me livrou de controles mais rígidos na imigração e na alfândega.

Nos três anos que passei em Lins (interior de São Paulo), uma das minhas atividades foi escrever um artigo resumindo a tese. É que o título de doutor só seria entregue pela Faculdade de Teologia de Louvain após a publicação desse artigo. O texto foi gentilmente traduzido pelo padre José Oscar Beozzo, colega e superior em Lins. Foi publicado na Revista Eclesiástica Brasileira de setembro de 1977 (HIGUET, 1977) de modo que pude receber o título em junho de 1978.

Com o título: "Escatologia e teologia da ação. Leitura crítica da Teologia Sistemática de Paul Tillich", a tese pretendia responder à questão fundamental da relação entre a realização final do Reino de Deus e a ação humana individual e coletiva a serviço da construção de um mundo mais justo e mais fraterno, libertado do sofrimento e da morte prematura. Tratava-se de mostrar que, apesar das aparências, a Teologia Sistemática era integralmente escatológica e que essa característica podia constituir um dos "fundamentos" teológicos da ação dos cristãos para superar as relações políticas de dominação no mundo. A primeira parte esforça-se por demonstrar a presença estrutural da dimensão escatológica em todas as seções do sistema teológico de Tillich. A segunda parte procura levantar a significação prática da escatologia teológica de Tillich, isto é, a questão das suas incidências sobre uma ética de transformação do mundo em vista de uma "Nova Terra" e de "Novos Céus".

Assim, por um lado, a escatologia de Tillich me pareceu sustentar uma prática transformadora e libertadora, graças à experiência do inesgotável poder do ser na criação divina, na dialética do ser e da vida, na criatividade humana histórica, na irrupção do Novo Ser em Cristo, superando a alienação, e no processo de elevação da história à eternidade. Por outro lado, cheguei à conclusão de que, pela sua obsessão da origem, pela sua insistência na experiência imediata do transcendente, pela insuficiência da autonomia do ser humano em relação ao Criador, pelo caráter transcendental da queda e do retorno, Tillich desvalorizava pro- 
fundamente a história e questionava gravemente a potência do ser como fundamento para a práxis. Isto deixava à mostra toda a ambiguidade dos "fundamentos ontológicos da esperança" na Teologia Sistemática e hipotecava pesadamente uma eventual retomada da escatologia de Tillich para uma teologia política, no sentido moderno do termo.

Trinta anos depois, em 2007, aproveitei um colóquio da Associação Paul Tillich de Expressão Francesa, para retomar a questão dos "Fundamentos da utopia e da esperança na Teologia Sistemática de Paul Tillich" (HIGUET, 2007a). ${ }^{7}$ Quis fazer um novo balanço da pertinência da teleologia ontológica como fundamento filosófico, e da escatologia existencial ou "realizada" como resposta. Pela teleologia - ou finalidade inerente ao próprio ser, à vida e à história humana - e graças à sua faculdade de superar indefinidamente o dado, o ser humano livre pode dar um sentido e uma direção às tendências imanentes da continuidade histórica, elevar o olhar na direção da novidade absoluta, da plenitude universal e não ambígua das potencialidades do ser. ${ }^{8}$ Apesar da falha originária da alienação da liberdade, a humanidade é capaz de colocar a pergunta da vida não ambígua, pois carrega em si uma estrutura de recepção do Incondicionado.

A resposta vem através da experiência existencial da presença de Deus como fundamento do ser, da ação do Novo Ser em Jesus como Cristo, da criação da Comunidade do Espírito e da constante elevação da história humana até a eternidade do Reino de Deus. Os momentos de irrupção do Incondicionado ou Kairói permitem que a esperança se mantenha de etapa em etapa e vise sempre a teonomia última (transparência total da cultura à manifestação do Incondicionado). Assim, a teleologia filosófica de Tillich e a sua escatologia teológica desembocam numa práxis libertadora em todas as esferas da vida humana. A experiência

\footnotetext{
7 A tradução portuguesa constitui o segundo capítulo do livro já mencionado: A teologia de Paul Tillich. Utopia, esperança e socialismo, enquanto o artigo resumindo a tese constitui o primeiro capítulo.

8 A teleologia pode ser eventualmente reconhecida pela ciência natural e pela filosofia, embora seja muito contestada na época atual, mas ela se fundamenta também na teologia cristã da criação.
} 
da "escatologia realizada" é, antes de tudo, uma experiência de discernimento ético-profético.

A pertinência de Tillich estaria mais, agora, no caráter existencial e simbólico da sua ontologia e na sua crítica radical do teísmo. O fundamento da utopia e da esperança situa-se mais na experiência existencial e na força da fé, do que na análise dos movimentos históricos. ${ }^{9} \mathrm{O}$ que na tese era uma censura - a desvalorização da história concreta - torna-se paradoxalmente positivo. Como Tillich, fomos otimistas demais em relação às realizações históricas e caímos na decepção "metafísica".

Sabemos agora que a revolução é ilusória e que fomos vítimas do mito do progresso. A rejeição por Tillich de toda lei histórica e de toda linha ascendente, que ligaria os kairói entre si, é precisamente o que dá valor, hoje, ao seu pensamento. O fim das utopias não deve nos levar ao desespero nem ao cinismo, mas a esperas históricas mais modestas e menos espetaculares. A teologia, a partir de uma experiência da fé e da esperança, pode sempre ter prolongamentos práticos, com a condição de estar articulada às ações dos mais diversos movimentos e grupos, que ela poderá orientar e julgar conforme os critérios do amor, do poder e da justiça. Ela receberá também deles lições de humildade, perante a ambiguidade sempre presente. Em vez de imaginar grandes projetos políticos irrealizáveis, ela poderá comprometer-se no tecido associativo dos movimentos sociais, culturais e ecológicos, ou ainda no diálogo inter-religioso, como fermento de paz e de amor. Ela poderá investir-se, enfim, na "invenção do cotidiano", segundo a bela expressão de Michel de Certeau. Para todo isso, Paul Tillich nos deixou indicações preciosas (HIGUET, 2017, p.108).

\section{Teologia e cultura}

Em 1977 e 1978, lecionei na Pós-Graduação em Teologia da Faculdade Nossa Senhora da Assunção, pertencente à Arquidiocese de São Paulo. A primeira disciplina oferecida contemplava o conteúdo da minha tese sobre Tillich. Na ocasião, tive como aluno um dos diretores do Instituto Metodista de Ensino Superior,

9 Do mesmo modo que Tillich conheceu, depois da segunda guerra mundial, o desencanto quanto à possibilidade de realizar a utopia socialista, estamos vivendo numa situação de fim das utopias e das ideologias. 
de São Bernardo do Campo, o professor Luiz Boaventura. Foi ele que possibilitou o meu ingresso no mesmo instituto em 1979. Passei a fazer parte do Programa de Pós-Graduação em Ciências da Religião no primeiro semestre de 1981, colaborando de modo ininterrupto até 2013. No começo, só tinha uma disciplina de três horas semanais (com mais três horas para a preparação), que precisava conciliar com um grande número de aulas de graduação em diversas instituições. Por outro lado, era o auge da Teologia da Libertação, e me dediquei quase exclusivamente ao pensamento latino-americano. Só voltaria a oferecer uma disciplina sobre o pensamento de Tillich em 1992: "História do pensamento cristão: a teologia da cultura, de Schleiermacher a Tillich". Em 1993, ofereci uma "Introdução à Teologia de Paul Tillich", a pedido da coordenação do programa.

A minha primeira publicação significativa foi um artigo na REB de 1994: "Atualidade da Teologia da Cultura de Paul Tillich". Estendia doravante a reflexão e a pesquisa à perspectiva da Teologia da Cultura. De certo modo, pode-se designar com esse termo a totalidade da teologia de Tillich, inclusive a Teologia Sistemática, já que o ponto de partida sempre se encontra numa análise e interpretação da "situação" cultural na qual o teólogo elabora o seu discurso. Contudo, a questão da política e do socialismo não seria abandonada. ${ }^{10}$

No segundo semestre de 1993, a pedido de alguns alunos, foi iniciado o Grupo de Pesquisa Paul Tillich, com os professores Jaci Maraschin e Rui Josgrilberg, que tinham também afinidades com o teólogo germano-americano. É importante ressaltar aqui o papel decisivo de um aluno do mestrado: Reynaldo Ferreira Leão, que foi o primeiro secretário do grupo. ${ }^{11} \mathrm{O}$ primeiro seminário foi organizado no Colégio Pio XI em novembro de 1994. Foi uma introdução à Teologia Sistemática. As conferências foram

\footnotetext{
10 Ver os textos do livro já mencionado.

11 O Reynaldo escreveu uma bela dissertação que, apesar das promessas da instituição, não chegou a ser publicada. Fiquei até com o texto revisado, pronto para ir para gráfica: "Espírito profético e razão institucional. Da experiência fundante à proscrição". O texto aplica a Richard Shaull o referencial tillichiano do princípio profético/protestante.
} 
publicadas em Estudos de Religião no 10 , número especial dedicado ao trigésimo aniversário do falecimento de Tillich. Escrevi o primeiro capítulo, sobre a introdução à teologia e a revelação (HIGUET, 1995 ). Durante o seminário, foi decidida a fundação de uma Sociedade Paul Tillich do Brasil. Os "Seminários em diálogo com o pensamento de Paul Tillich" se tornaram anuais, sendo realizados até hoje. ${ }^{12}$

Eis a lista dos temas:

1994 - Introdução à "Teologia Sistemática".

1995 - Mística no pensamento de Paul Tillich e nos Novos Movimentos Religiosos.

1996 - Cultura e Religião.

1997 - Demônios e Ambiguidades do Tempo presente.

1998 - Psicanálise, Psicologia Profunda e Experiência Religiosa.

1999 - A Situação Religiosa da Cultura no Brasil.

2001 - Religião e Religiões : Introdução ao Diálogo Inter-religioso.

2002 - As aventuras de Eros.

2003 - Paul Tillich e a Filosofia da sua época: marxismo, existencialismo, neokantismo, filosofia da vida.

2004 - Espiritualidade e Vida.

2005 - Religião e Arte.

2006 - A substância católica.

2007 - Ciência, tecnologia e religião.

2008 - Religião, teologia e literatura.

2009 - Paul Tillich e o pensamento pós-moderno: possibilidades e limitações.

2010 - Política globalizada na crise da civilização moderna.

2011 - GT Paul Tillich no congresso da ANPTECRE.

2012 - Ontologia e religião no pensamento contemporâneo, em diálogo com Paul Tillich.

2013 - A fé em Paul Tillich.

2014 - Teologia das religiões e pluralismo religioso.

2015 - Ética e Religião.

2016 - As ambiguidades da vida e da religião.

2017 - Religião e artes visuais.

A maioria dos temas está relacionada com a Teologia da Cultura. As conferências de 1998 foram publicadas em Estudos de

12 Carlos Eduardo Calvani publicou um pequeno histórico do grupo e da associação no livro "Teologia da Arte" (2010), sob o título A recepção do pensamento de Paul Tillich no Brasil, com bibliografia. 
Religião n ${ }^{\circ} 16$ (Cf. HIGUET, 1999). A partir de 2002, os textos que foram entregues saíram na revista Correlatio. Uma coletânea de artigos, organizada por Jaci Maraschin e por mim, saiu em 2006, com o título "A forma da religião - Leituras de Paul Tillich no Brasil” (HIGUET, 2006).

Em 2002, após diversas tentativas, iniciamos a publicação da revista eletrônica semestral Correlatio, hospedada no site da UMESP. O professor Maraschin assumiu a edição até o numero 9 e eu o substituí em seguida, até o presente número 34, com a ajuda de um corpo editorial constituído de docentes e discentes. Orientei um bom número de dissertações e teses dedicadas total ou parcialmente ao pensamento de Tillich. Algumas foram também orientadas pelos professores Rui Josgrilberg e Claudio Ribeiro. Organizamos uma sessão temática (depois GT) nos quatro últimos congressos da Anptecre (2011, 2013, 2015, 2017). O nosso colaborador Vitor Chaves de Souza colocou no ar o site www. paultillich.com.br. Temos também uma página Sociedade Paul Tillich no Facebook, administrada por Elton Sadao Tada.

Participei desde 1997 dos Colóquios da Associação Paul Tillich de expressão francesa, de dois em dois anos, e duas vezes de um Congresso internacional em Frankfurt. As publicações estão na bibliografia final deste artigo.

Voltando para a Teologia da Cultura, vejam a seguir uma breve apresentação da temática, a partir de textos meus, e um panorama das minhas principais publicações. A Teologia da Cultura trata das relações entre a religião e a cultura, segundo a fórmula que se tornou famosa: "A cultura é a forma da religião e a religião é a substância (ou conteúdo substancial) da cultura" (em "Filosofia da Religião", 1925).

Encontramos em Tillich duas principais concepções da religião: 1. No sentido estrito da palavra, a religião é uma vivência espiritual organizada em torno de ritos, crenças e devoções. Enquanto tal, a religião é uma esfera particular da cultura, entre outras, tais como a política, a economia, a arte, a ética, a ciência etc. 2. Mas Tillich dá a maior importância a uma concepção mais ampla da religião, como orientação do espírito que se volta para 
o Incondicionado: a religião é a experiência do Incondicionado. É o fato de ser tomado ou possuído por uma preocupação última ou incondicional. Por outro lado, o religioso é também o ambíguo, o irracional, o equívoco, marcado pela estrutura de alienação do ser humano. A religião como esfera separada de crenças e de culto existe por causa do pecado e da alienação, enquanto o Reino de Deus não vem. A religião é também marcada pelas ambiguidades da profanização e da demonização. De um lado, a institucionalização da religião a transforma num fenômeno cultural e moral entre outros; do outro, uma preocupação segunda é erguida ao nível da preocupação última, quando se identifica o portador do sagrado com o incondicional.

Durante os anos do primeiro ensino de Tillich (1919-1926), a teologia da cultura pretendia manifestar a substância ou conteúdo religioso da cultura, isto é, o que diz respeito à questão do absoluto e dos limites da existência humana, e que transparece nas funções teóricas (artes, ciências, filosofia) e práticas (direito, moral, educação, política, técnica) da cultura. Esta se identifica com o mundo propriamente humano do espírito, o conjunto das atividades criadoras do ser humano. Na Teologia Sistemática, a teologia da cultura é a "tentativa de analisar a teologia subjacente a todas as expressões culturais e de descobrir a preocupação última no fundamento de uma filosofia, de um sistema político, de um estilo artístico, de um conjunto de princípios éticos e sociais (TILLICH, 2005, p. 55)."

A chave para a compreensão teológica de uma criação cultural é o seu estilo. "Estilo é um termo que procede do campo das artes, mas é possível aplica-lo a todos os domínios da cultura. [...] $\mathrm{O}$ estilo de uma época se expressa em suas formas culturais, na escolha de objetos, nas atitudes de suas personalidades criativas, em suas instituições e costumes" (Ibid., p. 55). Além do estilo, vários outros conceitos importantes operam na análise religiosa da cultura. Em primeiro lugar, a noção de teonomia, na sua dialética com as ideias de autonomia e heteronomia. A cultura é "teônoma" quando o sentido supremo da existência ilumina todas as formas finitas de pensamento e ação, quando a cultura se torna trans- 
parente e que suas criações se tornam receptáculos de conteúdo espiritual. Ela é "heterônoma" quando a esfera religiosa procura dominar e controlar a criatividade cultural autônoma. Enfim, a cultura é "autônoma" quando os vínculos religiosos da civilização são rompidos, junto com o seu fundamento e o seu fim últimos, num completo vazio espiritual. A partir desses conceitos, a teologia da cultura torna-se análise teônoma da cultura, capaz de mostrar a presença do fundamento teônomo incondicional e sagrado em todas as épocas em todas as formas da cultura, até nas culturas predominantemente autônomas (ou seculares) ou heterônomas.

A ideia de teonomia deve ser completada pelas noções de Kairós e de "demônico". O Kairós é o tempo teônomo por excelência, é um tempo qualitativo, cheio de sentido, de tensões, de possíveis e impossíveis. Os momentos de Kairós são manifestações extraordinárias do eterno - aceitas, recebidas, reconhecidas - em pontos determinados da história, a qual se abre então ao incondicional. O “demônico" é

um princípio ambíguo, que contém um elemento criador e um elemento destruidor. É a face obscura do fundamento abissal, o lado tenebroso do divino, assim como o experimentou Lutero. Poderíamos dizer também que é a perversão do sagrado, o sagrado com um sinal negativo (TILLICH, apud GABUS, 1969, p.5).

"Ao contrário do satânico, que significa uma destruição completa da realidade, o demônico exprime um aspecto essencialmente dialético, positivo e negativo, do processo vital (GABUS, 1969, p. 5)."

É preciso mencionar enfim as noções de "princípio protestante" e de Gestalt (figura, estrutura vital) de graça. O princípio protestante é um princípio universalmente significativo, que se concretizou historicamente no protestantismo, mas que atua em todos os períodos históricos, já que expressa um aspecto da relação divino-humana. Ele contém o protesto divino e humano contra toda pretensão absoluta apresentada por realidades relativas, inclusive as próprias igrejas protestantes. A Gestalt de graça é um poder de criar formas novas e superiores (artísticas, litúrgicas, 
comunitárias, políticas etc.) além da atitude protestante crítica em relação às formas. Embora o princípio protestante rejeite toda identificação da graça com a realidade visível, a Gestalt de graça pode, contudo, ser objeto de uma "intuição imaginativa", como no caso da figura neotestamentária de Jesus enquanto Cristo. Ela é transparente a uma realidade que é mais que ela mesma. Ela pode manifestar-se através de todas as formas seculares ou profanas, com ousadia e risco. Isso diz respeito tanto ao conhecimento quanto à ação, tanto ao culto religioso quanto à cultura autônoma (cf. HIGUET, 2012b, p. 90-93).

Apresento a seguir alguns exemplos de análise religiosa da cultura presentes nas minhas produções entre 1994 e 2013.

Atualidade da teologia da cultura de Paul Tillich

- Análise da cultura da sociedade industrial.

$\mathrm{O}$ referencial aqui é a relação entre autonomia e teonomia. $\mathrm{Na}$ sociedade industrial - dominada pela razão instrumental, produto da razão autônoma - a nossa visão do mundo fica completamente objetivada e nós, seres humanos, estamos ameaçados de ser absorvidos por nossos produtos, perdendo assim a nossa dimensão pessoal e a dimensão de profundidade da nossa existência. Os símbolos religiosos se tornaram incapazes de evocar a transcendência e a realidade deixou de ser transparente ao eterno. O nosso mundo tornou-se um mundo de coisas, de meios incapazes de satisfazer o mundo dos fins. Nessa situação, a ação cristã, fundada na "Nova Realidade" em Cristo, terá como primeiro objetivo o reconhecimento da pessoa humano como fim. Para que isso se efetive, deveremos exigir mais justiça e igualdade nas estruturas sociais e econômicas, e o fim de todo exploração e opressão.

Os processos técnicos também podem tornar-se teônomos e abrir-se a um sentido último. Graças à arte e ao poder sublimado de Eros, os objetos produzidos pelo ser humano podem deixar de ser simples coisas. Podem se humanizados, reencontrar seu verdadeiro significado, servir novamente como meios para um fim transcendente, ajudar o ser humano a realizar-se como pessoa (HIGUET, 1994, p. 55). 
- Análise religiosa da situação do proletariado na sociedade capitalista.

A partir do referencial do princípio protestante ou profético, que traz o julgamento divino sobre qualquer realidade religiosa e cultural, impedindo a sua absolutização, Tillich completa a análise da situação do proletariado proposta pelo movimento socialista. O princípio protestante afirma que a situação humana está basicamente deformada, que a natureza humana está pervertida, em consequência de decisões destrutivas. Na situação proletária, a perversão da natureza humana manifesta-se enquanto perversão social e em forma de culpa social, e a total dependência do proletário em relação ao mercado é apenas uma consequência da perversão originária. É essa perversão demoníaca que determina a estrutura do capitalismo, causa imediata da situação proletária (Cf. HIGUET, 1994, p. 55).

- Natureza, símbolo e sacramento.

Tillich critica a razão técnica a partir da concepção da teonomia. Isto é, razão técnica ou instrumental priva a natureza da sua capacidade de carregar o poder transcendente e sacramental, por exemplo, através de símbolos naturais como a água, o fogo, a luz, o vento, as árvores, as pedras e as montanhas. Ao contrário, numa cultura teônoma, os símbolos religiosos valem-se da realidade finita para expressar a nossa relação com o infinito. A partir da revalorização do simbolismo natural do transcendente, abre-se um campo imenso para a preservação da natureza contra os seus produtos tecnocientíficos [...], para a superação da razão puramente instrumental e quantitativa na linguagem científica, [...] e para um diálogo com as religiões que privilegiam o encontro com o Sagrado na natureza.

Entre os exemplos dados para ilustrar sua teoria, Tillich fala do poder dos números, dos elementos da natureza orgânica (como os quatro elementos da filosofia grega e as pedras "preciosas"), da luz e das cores como expressão da transcendência, do poder da vida vegetal (árvores) e dos animais - com o seu aspecto trágico e demoníaco -, do sentido e do poder do corpo humano - no qual 
se concentram todas as potências da natureza, transcendendo as formas inferiores para chegar ao nível da liberdade e da história; enfim, de situações e configurações da natureza (astrologia); de ritmos naturais que adquiriram poder sagrado; e da "palavra" que é o processo natural mais importante para a atitude protestante em face da natureza (HIGUET, 1994, p. 58-59).

- Saúde, cura e salvação no pensamento de Paul Tillich.

A saúde e a cura, numa cultura teônoma, podem simbolizar a salvação, entendida como cura final cósmica e individual. A saúde corresponde à atualização autoprodutiva e autotranscendente da vida; a doença é uma forma de ambiguidade na alienação existencial e a cura remete à superação das ambiguidades na presença do Espírito divino. Trata-se de restabelecer o equilíbrio comprometido, na unidade de todas as dimensões da vida, inclusive na dimensão espiritual que abrange todas as outras. Assim, poderá haver reconciliação entre a medicina e a teologia (Cf. HIGUET, $\left.1999^{a}\right)$.

- Teologia da arte de Tillich.

Para Tillich, as criações artísticas expressam algo além delas, elas remetem ao fundamento incondicionado do ser, elas revelam algo do fundamento divino de todas as coisas, sendo assim indiretamente religiosas. Através de uma experiência do sagrado, que vai além da experiência de qualquer realidade cotidiana, as formas artísticas, tanto seculares quanto religiosas, fornecem as chaves da interpretação da existência humana. Especialmente através do estilo expressionista, Tillich descobriu que a arte constitui uma linguagem na qual a forma e o conteúdo substancial podem tornar-se o lugar da revelação do incondicionado, graças à destruição da forma e ao êxtase criador implicado neste processo. Para Tillich, o expressionismo é a forma na qual se dizem as rupturas na existência e a irrupção da transcendência. Nesse sentido, pode-se dizer que o expressionismo é uma arte profundamente protestante (Cf. HIGUET, 2012b, p. 90-96). 
Em diversos textos, usei o referencial tillichiano para analisar A crucifixão do retábulo de Issenheim, de Matthias Grünewald, a Guernica de Pablo Picasso, uma Crucifixão de Emil Nolde, a Via Crucis da Pampulha de Cândido Portinari (Cf. HIGUET, Grünewald; 2012b, p. 99-103; 2014e; Portinari).

Análise da religião como parte da cultura

- Jesus Cristo, símbolo de Kairós no pensamento de Paul Tillich e nos cultos afro-brasileiros

Jesus enquanto Cristo, como ápice e doador de sentido da história, é uma imagem, um símbolo, que cumpre uma função de mediação entre as três dimensões do tempo e da história: passado, presente e futuro, e entre o tempo e a eternidade, entre o divino e o humano. Na vida pessoal de Jesus, manifestou-se a imagem da humanidade essencial, sem ser apagada pelas condições da existência. Sem assumir uma cristologia pluralista, Tillich abre a porta ao reconhecimento de outras imagens do Novo Ser, fora do contexto cristão, com as mesmas propriedades de simbolização que a imagem de Jesus. A figura sincrética de Cristo, nas religiões afro-brasileiras, desempenha dignamente a função de simbolizar momentos existenciais de revelação, libertação e salvação na história de sofrimento e luta dos negros e afrodescendentes (Cf. HIGUET, 2005 a).

- Ambiguidade das imagens religiosas no catolicismo popular à luz da teologia de Paul Tillich: o exemplo de Nossa Senhora Aparecida no Brasil.

Entre as ambiguidades da religião, a atenção se concentrou, neste artigo, no culto dos santos, em particular da Virgem Maria e no lugar reconhecido às imagens religiosas no catolicismo. A primeira parte desenvolve o exemplo da imagem e da devoção à Nossa Senhora Aparecida, padroeira do Brasil, partindo de uma análise histórica da devoção, para detectar suas ambiguidades : a ambiguidade do culto autêntico e da idolatria, do maravilhoso e do milagres ; a ambiguidade da fé popular e da religião institucional, em particular os conflitos de interpretação entre autoridades dou- 
trinais e fiéis, assim como as manipulações político-eclesiásticas e ideológicas. A segunda parte faz uma leitura dessas ambiguidades à luz da teologia de Paul Tillich : ambiguidade do sagrado (divino-demônico, heteronomia-autonomia) e das suas expressões simbólicas (idolatria-profanização, redução do símbolo ao conceito), ambiguidade da santidade e da devoção aos santos (Cf. HIGUET, 2017b).

\section{Em busca dos fundamentos da teologia da cultura}

- Ontologia e religião na teologia da cultura de Paul Tillich - A contribuição da ontologia para a análise religiosa da cultura.

Este artigo tentou mostrar como a teologia da cultura de Paul Tillich, em particular a sua teologia da arte, está intimamente relacionada com a sua ontologia existencial e dinâmica. A experiência do absoluto ou incondicionado que irrompe nas formas da cultura, afirmando e negando ao mesmo tempo essas formas, é entendida por Tillich como experiência ontológica fundamental, experiência do ser e do além-do-ser, que suscita ao mesmo tempo angústia e coragem. Estes conceitos são conceitos ontológicos, enraizados no poder do ser que resiste ao não ser. Podemos dizer a mesma coisa dos principais conceitos que estruturam a teologia da cultura, como forma, conteúdo substancial, demônico, teonomia, alienação, estilo religioso. Ilustrei o meu propósito com vários exemplos tirados das artes existenciais, nos campos da literatura e das artes plásticas (Cf. HIGUET, 2012 a).

Fora da Teologia da Cultura, mas em relação com ela, propus também algumas reflexões epistemológicas e metodológicas: $\mathrm{O}$ método da Teologia Sistemática, O método da filosofia da religião, O campo e o estudo da religião à luz do pensamento de Paul Tillich. Gostaria de terminar com algo que me atraiu desde as minhas primeiras leituras de Tillich: a sua tentativa de pensar Deus fora das categorias da ontoteologia, superando assim o teísmo tradicional. Aliás, está em sintonia com a cultura da nossa modernidade tardia. 
A reflexão está no artigo "Falar de Deus no limite dos tempos: A contribuição de Paul Tillich à superação do teísmo na modernidade tardia”. A teologia de Paul Tillich, através da sua superação do teísmo, da generalização da linguagem simbólica na teologia e da superação da "onto-teo-logia" antecipou de certo modo o abandono de formas de linguagem e pensamento vinculadas a uma época dominada pela leitura literal dos mitos e símbolos - isto é, sua transformação em conceitos - e pela autoridade dogmática irrecusável. Tillich contribuiu assim à reinterpretação e re-estruturação do patrimônio simbólico das religiões, na nova situação de conhecimento e dos novos parâmetros de interpretação, facilitando assim o "trânsito" inevitável em que nos encontramos.

Em Tillich, a crítica do teísmo acompanha a crítica do supranaturalismo, que separa Deus como um ser, o ser supremo, dos demais seres, ao lado e acima dos quais ele tem a sua existência. Esta interpretação transforma a infinitude de Deus em finitude dependente das categorias de espaço, tempo, causalidade e substância. Ao contrario, precisamos afirmar que Deus não seria Deus se não fosse o fundamento criativo de tudo o que tem ser, que, de fato, ele é o poder infinito e incondicional do ser. Neste sentido, Deus não está ao lado das coisas nem "acima" delas, mas está mais próximo das coisas do que elas de si mesmas. Ele é o seu fundamento criativo, aqui e agora, sempre e em todo lugar. Dizer que Deus é transcendente não significa que se deva estabelecer um "supermundo" de objetos divinos. A afirmação fundamental sobre Deus, que ele é o ser-em-si ou o poder do ser, exclui que ele seja um ente. Um Deus que é um ente ao lado de outros entes é simplesmente um ídolo, uma coisa cósmica ao lado de outras. O teísmo, em todas as suas formas, é superado pela experiência da fé absoluta, ou o estado de ser possuído pelo "Deus além de Deus" ou o "Deus acima de Deus" (Cf. HIGUET, 2014b).

\section{Considerações finais}

Ao longo deste breve tempo de escuta ou de leitura, procurei conduzir o ouvinte ou o leitor através de alguns meandros 
da minha convivência com o pensamento de Paul Tillich. Quis apresentar, não um modelo, mas um testemunho de itinerário filosófico-teológico, conforme me foi pedido. Deste modo, deixei de lado vários centros de interesse e objetos de pesquisa que atraíram a minha atenção ou me foram impostos pelas exigências do ensino ou do momento histórico. Basta mencionar a filosofia da religião, a teologia da libertação, a história e a teologia das religiões e do pluralismo religioso, a epistemologia da teologia e das ciências da religião, a hermenêutica e a fenomenologia, a mística, modernidade e pós-modernidade e, nos últimos anos, a cultura visual e a interpretação das imagens religiosas. Mesmo assim, o pensamento de Tillich sempre esteve presente como interlocutor e como porto seguro.

Sempre tive a preocupação de atualizar e prolongar o pensamento de Paul Tillich, fazendo dele uma ferramenta de análise e reflexão sobre ideias e situações políticas, culturais e religiosas do tempo presente, especialmente no Brasil. Incentivei, na orientação de mestrandos e doutorandos e na organização dos "Seminários em diálogo com o pensamento de Paul Tillich", os encontros com a filosofia, a ciência, as artes (pintura, literatura, música popular) e as religiões presentes no Brasil. Do mesmo modo que Tillich se opunha ao fundamentalismo bíblico e religioso, tentei evitar o fundamentalismo tillichiano. Não hesitei em criticar o meu teólogo predileto e em mostrar os seus limites, quando necessário.

Alguns desses limites me foram lembrados na discussão que seguiu a conferência, como a sua pertença a uma tradição cultural, filosófica e teológica bem distante das raízes culturais brasileiras e, além disso, dominadora e destruidora das culturas do mundo colonizado. Sem contar a distância temporal cada vez maior. É claro que não podemos ler as obras de Tillich como livros de receitas. É preciso ficar atento, mais do que no passado, à complexidade, às diferenças e aos efeitos de dominação nas relações da cultura europeia com a(s) cultura(s) latino-americana(s) e brasileira(s). A mesma coisa vale para as religiões, inclusive para as formas diversas de cristianismo católico e protestante e suas teologias. Usar o pensamento de Tillich sem cuidados pode levar à universalização 
inconsciente das tradições dominantes. O próprio Tillich reconheceu o "provincianismo" da sua formação intelectual e do seu pensamento. Ele não poupou os esforços para encontrar a cultura norte-americana na sua especificidade, superando o saudosismo intelectual e cultural. Abriu-se às ciências sociais, à história das religiões, à psicanálise e à psicologia profunda e, nos últimos anos, às religiões orientais, em particular ao budismo japonês. Esteve sempre presente na mídia, a revista Time chegando a lhe dedicar a capa de um número.

Ao ler Tillich, precisamos adotar os mesmos cuidados que tomamos na leitura de Aristóteles, Tomás de Aquino, Kant, Marx, e também Homero, Dante, Shakespeare, Machado de Assis ou Guimarães Rosa. Trata-se de praticar conscientemente a "antropofagia”, como fez Macunaíma. Por outro lado, precisamos desfazer a ilusão de poder restaurar a "pureza original” das raízes religiosas e culturais anteriores à colonização. Todas as culturas e religiões são híbridas e sincréticas. Podemos lamentar, mas não apagar, o fato de que a história da humanidade é uma história de encontros e desencontros, que contém mais violência física e simbólica do que paz e harmonia. Tillich nos ajuda a tomar consciência das ambiguidades irredutíveis da vida humana, inclusive das formas do sagrado e do próprio pensamento dele.

Outra pergunta: o estudo de Tillich cabe num programa de Ciências da religião? O fato é que a filosofia e a teologia estão presentes em vários Programas de pós-graduação em Ciências da religião no Brasil. A Capes e a Anptecre reconheceram a sua relevância nestes programas. Tentei mostra-lo no artigo intitulado "A teologia em programas de ciências da religião" (HIGUET, $2006^{\mathrm{a}}$ ), usando parcialmente o pensamento tillichiano. Para Tillich, a teologia é a parte sistemática e normativa da ciência da religião. Como teologia da cultura, ela estuda o teor religioso de toda cultura e de toda forma cultural. Assim, ela estará presente como ciência hermenêutica, de preferência não confessional e crítica das ideologias, inclusive no seu próprio seio. Nesse sentido, percebi que, para muitos dos meus alunos, o pensamento de Tillich foi um caminho privilegiado na superação do fundamentalismo. 
E a vida continua. No final de 2013, chegou ao fim um grande ciclo, quando tive que encerrar uma carreira de trinta e quatro anos na UMESP. Estou imensamente grato ao professor Claudio de Oliveira Ribeiro, participante da primeira hora, que assumiu então a responsabilidade e a supervisão do Grupo de pesquisa Paul Tillich de Teologia e Cultura. Com a Associação Paul Tillich do Brasil, participamos dos congressos da Anptecre em 2015 e 2017 e organizamos quatro "Seminários em diálogo com pensamento de Paul Tillich". Organizei um dossiê sobre a atualidade do pensamento de Paul Tillich, com participações internacionais, na revista Estudos de Religião. Estamos preparando o seminário de 2018. Só o futuro nos dirá até quando haverá continuidade, mas sabemos que, aos trancos e barrancos, conseguimos cumprir a nossa parte.

\section{Referências bibliográficas}

\section{Bibliografia do autor}

\section{Artigos completos publicados em periódicos}

HIGUET, E. A. Interpretação de imagens religiosas: A Via Sacra da Pampulha de Cândido Portinari. Plural Pluriel, v. 7, p. 1-15, 2016 a.

HIGUET, E. A. Apresentação do dossiê: Atualidade do pensamento de Paul Tillich.

Estudos de Religião, v. 30, p. 155-164, 2016b.

HIGUET, E. A. Saúde, doença e cura no pensamento de Paul Tillich: reflexões teológicas e pastorais. Revista Pistis \& Praxis, v. 6, p. 167-188, 2014a.

HIGUET, E. A. Além do teísmo. Falar de Deus no limite dos tempos A partir da teologia de Paul Tillich. Voices, v. 37, p. 121-131, 2014b.

HIGUET, E. A. Falar de Deus no limite dos tempos: A contribuição de Paul Tillich à superação do teísmo na modernidade tardia. Correlatio (Online), v. 13, p. 29-50, 2014c.

HIGUET, E. A. O capitalismo não é uma religião. Correlatio (Online), v. 13, p. $165-170,2014 d$. 
HIGUET, E. A. A representação do Cristo no expressionismo alemão. Observatório da religião, v. 1, p. 76-91, 2014e.

HIGUET, E.A. Tendências Pluralistas na Teologia das Religiões de Paul Tillich. Correlatio (Online), v. 13, p. 7-24, 2014 f.

HIGUET, E. A. Ontologia e religião na teologia da cultura de Paul Tillich . A contribuição da ontologia para a análise religiosa da cultura. Correlatio (Online), v. 11, p. 5-21, 2012a.

HIGUET, E. A. Os métodos da filosofia da religião de Paul Tillich. Correlatio (Online), v. 10, p. 27-41, 2011.

HIGUET, E. A. A crucifixão de Matthias Grünewald à luz de uma teologia protestante da imagem. Correlatio (Online), Vol. 8, no 16, 2009, p. 74-94.

HIGUET, E. A. As relações entre teologia e cultura no pensamento de Paul Tillich. Correlatio (Online), v. 7, p. 123-143, 2008.

HIGUET, E. A. A teologia em programas de ciências da religião. Correlatio (online), Vol. 5, no 9, p. 37-51, 2006a.

HIGUET, E. A. Jesus, símbolo de kairos no pensamento de Paul Tillich e nos cultos afro-brasileiros. Correlatio (São Bernardo do Campo), São Bernardo do Campo - SP, v. 4, n.7, p. 35-43, 2005a.

HIGUET, E. A. A teologia "apologética" da cultura de Paul Tillich: profundidade e superfície na busca do sentido. Correlatio (São Bernardo do Campo), v. 04, n.08, p. 80-90, 2005b.

HIGUET, E. A. Devoção e Romaria à Santíssima Trindade. Um olhar simpático a partir de Paul Tillich. Correlatio (São Bernardo do Campo), v. 3, n.5, p. 01-10, 2004a.

HIGUET, E. A. Espiritualidade e política: a espera. Correlatio (São Bernardo do Campo), v. 3, n.6, p. 104-109, 2004b.

HIGUET, E. A. Misticismo e Sincretismo na Espiritualidade Ecológica Brasileira; Justificação e Crítica a partir do Pensamento de Paul Tillich. Estudos de Religião, São Bernardo do Campo - SP, v. 15, n.20, p. 135-155, 2002a.

HIGUET, E. A. Dogmatik, por Paul Tillich (resenha). Correlatio (São Bernardo do Campo), v. 1, n.1, 2002b.

HIGUET, E. A. Alguns aspectos do catolicismo brasileiro atual - Considerações a partir da visão da modernidade em Paul Tillich. Correlatio (São Bernardo do Campo), São Bernardo do Campo - SP, v. 1, n.1, 2002c.

HIGUET, E. A. Amor divino e/ou amor humano? Amor cristão e/ou amor pagão? O resgate do erótico no Pensamento de Paul Tillich e na Teologia Feminista. Estudos de Religião, São Bernardo do Campo - SP, v. 16, n.22, p. 141-161, 2002d. 
HIGUET, E. A. A força de Eros no pensamento ético e político de Paul Tillich. Correlatio (São Bernardo do Campo), v. 1, n.2, 2002e.

HIGUET, E. A. PINHEIRO, J.S. Ética e espírito profético - Revisitando a história com Paul Tillich (Resenha). Correlatio (São Bernardo do Campo), v. $1, \mathrm{n} .2,2002 \mathrm{f}$.

HIGUET, E. A. La théologie de la culture en Amérique latine. Foi et Vie (Paris), Paris, França, v. 100, n.01, p. 47-61, 2001 a.

HIGUET, E. A. Saúde, cura e salvação no pensamento de Paul Tillich. Estudos de Religião, São Bernardo do Campo - SP, v. 13, n.16, p. 75-85, 1999a.

HIGUET, E. A. Tillichforschung In Brasilien. Dialog - Mittteilungsblatt der deutschen Paul Tillich Gesellschaft, Friedberg, v. 2, n.23, p. 8-9, 1996.

HIGUET, E. A. O Método da Teologia Sistemática de Paul Tillich - A Relação da Razão e da Revelação. Estudos de religião, v. 10, n.10, p. 37-54, 1995a.

HIGUET, E. A. Teologia da Esperança - Primeiro Balanço Crítico. Estudos de religião, v. 10, n.11, p. 27-52, 1995 b.

HIGUET, E. A. Atualidade da Teologia da Cultura de Paul Tillich. Revista Eclesiástica brasileira, v. 54, n.213, p. 50-61, 1994.

HIGUET, E. A. Libertação política na teologia de Paul Tillich. Ata \& Ato Revista do Instituto Anglicano de Estudos Teológicos. Ano 1, n 1, 1980, p. 8-11.

HIGUET, E. A. Escatologia e Teologia da Ação. A Teologia Sistemática de Paul Tillich. Revista eclesiástica brasileira, v. 37, n.147, 1977, p. 525-568.

\section{Livros publicados/organizados}

HIGUet, E. A. A teologia de Paul Tillich, Utopia, esperança e socialismo. São Paulo/Belém: Fonte Editorial/UEPA, 2017a.

HIGUET, E. A.; MARASCHIN, J. C. (Org.). A forma da religião - Leituras de Paul Tillich no Brasil. São Bernardo do Campo - SP: Universidade Metodista de São Paulo, 2006b.

HIGuEt, E. A. (Org.) Teologia e Modernidade. São Paulo: Novo Século/ Fonte Editorial, 2005c.

\section{Capítulos de livros}

HIGUET, E. A. Ambigüité des images religieuses dans le catholicisme populaire à la lumière de la théologie de Paul Tillich : l'exemple de Notre- 
Dame «Aparecida » au Brésil. In : Marc Dumas, Jean Richard, Bryan Wagoner (eds.). Les ambigüités de la vie selon Paul Tillich. Trabalhos oriundos do XXI Colóquio internacional da Associação Paul Tillich de expressão francesa. Berlin/Boston: Walter de Gruyter, 2017b, p. 275-290.

HIGUET, E. A. Saúde, doença e cura no pensamento de Paul Tillich: reflexões teológicas e pastorais. In: Márcio Luiz Fernandes; Mary Rute Gomes Esperandio; Sérgio Rogério Azevedo Junqueira. (Org.). Espiritualidade, Saúde e cultura. A teologia nas fronteiras. Curitiba, PR: Juruá, 2016c, p. 113-131.

HIGUET, E. A. Communauté politique et Règne de Dieu. Théologie et socialisme chez Tillich et Barth. In: Mireille Hébert; Anne Marie Reijnen. (Org.). Paul Tillich et Karl Barth: Antagonismes et accords théologiques. Wien, Aústria: Lit-Verlag. Dr. W. Hopf, 2016d, p. 45-65.

HIGUET, E. A. Interprétation politique de l'histoire dans la théologie de la libération et dans la pensée de Paul Tillich: le rapport au marxisme. In: Marc Dumas; Martin Leiner; Jean Richard. (Org.). Paul Tillich - Interprète de l'histoire. Berlin: Lit-Verlag, Dr. W. Hopf, 2013, p. 75-96.

HIGUET, E. A. Interpretação das imagens na teologia e nas ciências da religião. In: Paulo Augusto de Souza Nogueira. (Org.). Linguagens da religião. Desafios, métodos e conceitos centrais. São Paulo - SP: Paulinas, 2012b, p. 69-106.

HIGUET, E. A. O campo e o estudo da religião à luz do pensamento de Paul Tillich. In: José J. Queiroz; Maria Luiza Guedes; Angela Maria Lucas Quintiliano. (Org.). Religião, modernidade e pós-modernidade. Interfaces, novos discursos e linguagens. São Paulo: Ideias e Letras, 2012c, p. 13-33.

HIGUET, E. A. Religião e Cultura na ótica de Paul Tillich. In: Adailton Maciel Augusto. (Org.). Ainda o sagrado selvagem - Estudos em homenagem a Antônio Gouvêa Mendonça. São Paulo: Fonte Editorial \& Paulinas, 2010, p. 219-241.

HIGUET, E. A. Les fondements de l'utopie et de l'espérance. In: XVIIe colloque international Paul Tillich, 2009, Fribourg (Suiça). Les peurs, la mort, l'espérance: autour de Paul Tillich. Berlin: Lit-Verlag, 2007a , v. 21. p.171182.

HIGUET, E. A. La fonction «pastorale» de la théologie apologétique ou le temps et l'éternité dans la culture. In: XVIe Colloque Internaational Paul Tillich, Montpellier 2005. Paul Tillich, prédicateur et théologien pratique. Berlin: Lit Verlag, 2007b, v. 18. p. 131-142.

HIGUET, E. A. Amor divino ou amor humano? Amor cristão ou amor pagão? O resgate do erótico no pensamento de Paul Tillich e na teologia feminista. In: Etienne Alfred Higuet, Jaci Correia Maraschin (Org.). A forma da religião - Leituras de Paul Tillich no Brasil. São Bernardo do Campo: Universidade Metodista de São Paulo, 2006c, p. 135-153. 
HIGUET, E. A. Jesus der Christus als Symbol des jetzigen Kairos bei Paul Tillich und in den Religionen Brasiliens. In: X. Internationales Paul-Tillich-Symposium, 2006d, Frankfurt/Main. Christus Jesus - Mitte der Geschichte!? Wien / Berlin: Lit-Verlag, 2006c, v. 13. p. 328-343.

HIGUET, E. A. Teologia e Modernidade: Introdução geral ao tema. In: HIGUET, E. A (Org.). Teologia e Modernidade. São Paulo: Fonte Editorial, 2005d, p. 09-31.

HIGUET, E. A. Le «socialisme religieux» de Paul Tillich et le socialisme brésilien de «l'ère Lula». Essai de lecture comparative. In: Éthique sociale et socialisme religieux. $15^{\circ}$ Colloque International Paul Tillich, 2005, Toulouse (França). Éthique sociale et socialisme religieux. Münster (Alemanha): Lit-Verlag, 2003,vol. 14, p. 233-249.

HIGUET, E. A. Die trinitarischen Symbole im brasilianischen Volkskatholizismus. Religionsgeschichtliche und theologische Interpretation in der Perspektive Tillichs. In: IX. Internationales Paul-Tillich-Symposium, 2004, Frankfurt/ Main. Trinität und/oder Quaternität - Tillichs Neuerschliessung der trinitarischen Problematik. Münster: Lit Verlag, 2002g, p. 338-350.

HIGUET, E. A. Évolutions récentes du catholicisme au Brésil: un rapport ambigu à la modernité. In: XIVe Collolque International Paul Tillich, 2002, Marseille. Mutations religieuses de la modernité tardive. Münster/Hamburg/ London: Lit-Verlag, 2001b, v. 14, p. 140-153.

HIGUET, E. A. Mystizismus und Synkretismus in der neuen Spiritualität Brasiliens: Rechtfertigung und Kritik in der Perspektive der Theologie Tillichs. In: Mystisches Erbe in Tillichs philosophischer Theologie - VIII.Internationales Paul-Tillich-Symposium, 2000, Frankfurt/Main. Beiträge des VIII. Internationalen Paul-Tillich-Symposiums Frankfurt/Main 2000. Münster-Hamburg-London: Lit Verlag, 2000, v. 3. p. 438-453.

HIGUET, E. A. A Experiência Religiosa no Método Teológico. In: ANJOS, M. F. dos (Org.) Sob o fogo do Espírito. São Paulo: Soter/Paulinas, 1998, p. 149-163.

\section{Trabalhos completos publicados em anais de congressos}

HIGUET, E. A.. Heurs et Malheurs de la pensée utopique. Quelle utopie pour surmonter la crise? Une réflexion à partir de Tillich et de Hinkelhammert. In: Treizième colloque international Paul Tillich - Amour, pouvoir et justice, 1999. Lille (França): Association Paul Tillich d'expression française, 1999b. v. 5. p. 51-64. 
HIGUET, E. A.. La Méthode de La Théologie de La Culture Au Brésil. In: XIIè Colloque International Paul Tillich - La méthode de Paul Tillich. Luxembourg, 1997, v. 12. p.157-182.

\section{Outros autores}

GABUS, J-P. Introduction à la théologie de la culture de Paul Tillich. Paris : PUF, 1969.

TILLICH, P. Auf der Grenze. Aus dem Lebenswerk Paul Tillichs. Taschenbuchausg. München/Hamburg: Siebenstern, 1965.

TILLICH, P. Der Protestantismus als Kritik und Gestaltung. Hrsg. Renate Albrecht. Taschenbuchausg. München/Hamburg: Siebenstern, 1966.

TILLICH, P. Für und wider den Sozialismus. Hrsg. Wolf-Dieter Marsch. München/Hamburg: Siebenstern Taschenbuch, 1969.

TILLICH, P. Teologia sistemática. Trad. Getúlio Bertelli e Geraldo Korndörfer. Revisão Ênio Mueller. São Leopoldo, RS: Sinodal, 2005, 5ª ed. Revista. 